NASA/TM-2000-210028

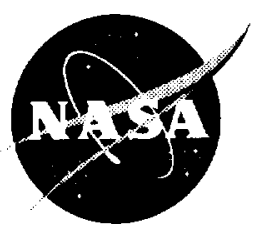

\title{
A Hybrid Satellite-Terrestrial Approach to Aeronautical Communication Networks
}

Robert J. Kerczewski, Gerald J. Chomos, James H. Griner, Steven W. Mainger, and Konstantinos S. Martzaklis

Glenn Research Center, Cleveland, Ohio

Brian A. Kachmar

Analex Corporation, Brook Park, Ohio 
Since its founding, NASA has been dedicated to the advancement of aeronautics and space science. The NASA Scientific and Technical Information (STI) Program Office plays a key part in helping NASA maintain this important role.

The NASA STI Program Office is operated by Langley Research Center, the Lead Center for NASA's scientific and technical information. The NASA STI Program Office provides access to the NASA STI Database, the largest collection of aeronautical and space science STI in the world. The Program Office is also NASA's institutional mechanism for disseminating the results of its research and development activities. These results are published by NASA in the NASA STI Report Series, which includes the following report types:

- TECHNICAL PUBLICATION. Reports of completed research or a major significant phase of research that present the results of NASA programs and include extensive data or theoretical analysis. Includes compilations of significant scientific and technical data and information deemed to be of continuing reference value. NASA's counterpart of peerreviewed formal professional papers but has less stringent limitations on manuscript length and extent of graphic presentations.

- TECHNICAL MEMORANDUM. Scientific and technical findings that are preliminary or of specialized interest, e.g., quick release reports, working papers, and bibliographies that contain minimal annotation. Does not contain extensive analysis.

- CONTRACTOR REPORT. Scientific and technical findings by NASA-sponsored contractors and grantees.
- CONFERENCE PUBLICATION. Collected papers from scientific and technical conferences, symposia, seminars, or other meetings sponsored or cosponsored by NASA.

- SPECIAL PUBLICATION. Scientific, technical, or historical information from NASA programs, projects, and missions, often concerned with subjects having substantial public interest.

- TECHNICAL TRANSLATION. Englishlanguage translations of foreign scientific and technical material pertinent to NASA's mission.

Specialized services that complement the STI Program Office's diverse offerings include creating custom thesauri, building customized data bases, organizing and publishing research results ... . even providing videos.

For more information about the NASA STI Program Office, see the following:

- Access the NASA STI Program Home Page at http://www.sti.nasa.gov

- E-mail your question via the Internet to help@sti.nasa.gov

- Fax your question to the NASA Access Help Desk at (301) 621-0134

- Telephone the NASA Access Help Desk at (301) 621-0390

- Write to: NASA Access Help Desk NASA Center for AeroSpace Information 7121 Standard Drive Hanover, MD 21076 


\section{A Hybrid Satellite-Terrestrial Approach to Aeronautical Communication Networks}

Robert J. Kerczewski, Gerald J. Chomos, James H. Griner, Steven W. Mainger, and Konstantinos S. Martzaklis

Glenn Research Center, Cleveland, Ohio

Brian A. Kachmar

Analex Corporation, Brook Park, Ohio

Prepared for the

18th International Communications Satellite Systems Conference sponsored by the American Institute of Aeronautics and Astronautics Oakland, California, April 10-14, 2000

National Aeronautics and

Space Administration

Glenn Research Center 
Available from

NASA Center for Aerospace Information 7121 Standard Drive

Hanover, MD 21076

Price Code: A03
National Technical Information Service 5285 Port Royal Road Springfield, VA 22100 


\title{
A HYBRID SATELLITE-TERRESTRIAL APPROACH TO AERONAUTICAL COMMUNICATION NETWORKS
}

\author{
Robert J. Kerczewski, Gerald J. Chomos, James H. Griner, \\ Steven W. Mainger, and Konstantinos S. Martzaklis \\ National Aeronautics and Space Administration \\ John H. Glenn Research Center \\ Cleveland, Ohio \\ and \\ Brian A. Kachmar \\ Analex Corporation \\ Brook Park, Ohio
}

\begin{abstract}
Rapid growth in air travel has been projected to continue for the foreseeable future. To maintain a safe and efficient national and global aviation system, significant advances in communications systems supporting aviation are required. Satellites will increasingly play a critical role in the aeronautical communications network. At the same time, current ground-based communications links, primarily very high frequency (VHF), will continue to be employed due to cost advantages and legacy issues. Hence a hybrid satellite-terrestrial network, or group of networks, will emerge. The increased complexity of future aeronautical communications networks dictates that system-level modeling be employed to obtain an optimal system fulfilling a majority of user needs. The NASA Glenn Research Center is investigating the current and potential future state of aeronautical communications, and is developing a simulation and modeling program to research future communications architectures for national and global aeronautical needs. This paper describes the primary requirements, the current infrastructure, and emerging trends of aeronautical communications, including a growing role for satellite communications. The need for a hybrid communications system architecture approach including both satellite and ground-based communications links is explained. Future aeronautical communication network topologies and key issues in simulation and modeling of future aeronautical communications systems are described.
\end{abstract}

\section{Introduction}

Nationally and globally, rapid growth in the aviation industry is being accompanied by longer and more frequent flight delays and increased concerns about the safety of the air transportation system. Currently, airlines carry an average of about 4 million passengers daily, and the International Civil Aviation Organization (ICAO) projects traffic to increase at an annual rate of $5.5 \%$ through $2005^{1.2}$. The increase in aviation traffic is straining the capacity of the national and global airspace system. In addition, without significant reduction of the aviation accident rate, the frequency of aviation accidents will quickly grow to an unacceptable level.

Two major NASA aviation programs have been started to address these issues. The Aviation System Capacity Program has a goal of increasing the throughput capacity of the National Airspace System by a factor of 3 within 10 years. The Aviation Safety Program's goal is to reduce the fatal aviation accident rate by $80 \%$ by 2007 and by $90 \%$ by 2022 .

Data dissemination has been identified as a key issue in addressing both capacity and safety issues. NASA's John H. Glenn Research Center has the lead role in identifying the communications requirements and technology solutions for improving data dissemination in the aeronautical world. In particular, moving data into and out of the cockpit will enable advanced air traffic management methods and graphical data displays for improved aircraft situational awareness.

A key technology being developed under the Aviation Capacity Program is called Free Flight. In the free flight environment, aircraft have the freedom to select flight paths and other parameters in real time. Air traffic controllers would then function as aircraft separation managers ${ }^{3}$. 


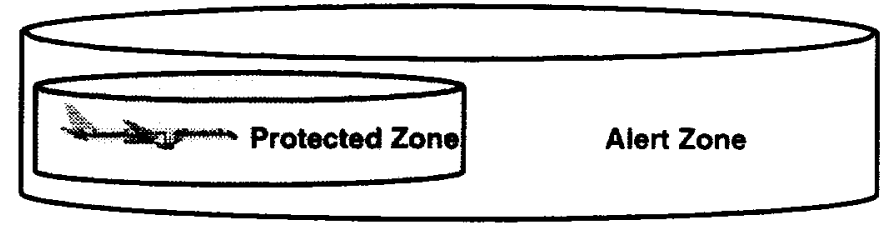

Figure 1 - Free flight concept.

Figure 1 shows how aircraft in a free-flight system would be required to maintain protected zones and would be able to choose routes freely providing that alert zones of aircraft do not intersect. In the most advanced free flight scenario, flight management computers on each aircraft would receive information on aircraft within its region. Potential conflicts between aircraft would be predicted, and negotiations between affected aircraft would enable resolution of conflicts with minor adjustments in airspeed, altitude, and/or trajectory.

It is estimated that airlines could save $\$ 3.5$ billion or more annually in a free flight environment by reducing flight times and eliminating ground and landing delays caused by the inflexibility in planning and adjusting the timing of arrivals and departures ${ }^{4}$. This is sufficient economic incentive for airlines to support free flight initiatives. Although the level of autonomy of individual aircraft in a free flight environment, or the division of responsibility between the ground and the flight deck, is an issue of much debate, the amount of data required to pass between aircraft and the ground, or between aircraft in flight, will be substantially greater than current air-to-ground communications

In the Aviation Safety Program, NASA Glenn is addressing the problem of getting better weather data into the cockpit. The current communication infrastructure is capable of supporting the transmission of only basic text-based weather messages. Some new commercial based services are becoming available to transmit some weather graphics into the cockpit, primarily weather radar composite graphics such as one can now easily obtain over the Internet. However, in order to make a significant reduction in weather-related aviation accidents, the United States National Aviation Weather Program Council has recommended improvements in aviation weather forecasting and nowcasting for such weather hazards as convective activity (convective storms), lightning, low altitude wind shear, clear air and other turbulence, icing, microburst and gust front activity, widespread low visibility, and volcanic ash ${ }^{5}$. NASA and other organizations are developing weather products and information presentation methods to meet these needs. However the communications requirements for transmitting such information in a timely and accurate manner will be much greater than for currently available weather products.

In addressing the increased aeronautical communications needed to meet the goals of the Aviation Capacity and Safety Programs, it is necessary to take a broader look at all aeronautical communications. Since future communications links and networks will likely carry aggregated traffic for a variety of applications, the capacity and safetyrelated traffic must be considered within the context of the entire aeronautical communications system. The following sections describe the basic set of aeronautical communications requirements and current and near-term communications infrastructures. Next, observed trends in the development of future aeronautical communications are discussed, followed by the growing role of satellite communications in aviation. The need for aeronautical communications systems consisting of a hybrid of satellite and ground based communications links is explained, and aspects of network topologies that will be applied to future aeronautical communications are described. In the final section, the key issues which must be addressed in analyzing aeronautical communications systems and networks are covered.

\section{Aeronautical Communications Requirements}

Nearly all aeronautical communications can be classified in one of four categories: Air Traffic Control/Air Traffic Management (ATC/ATM), Airline Operations Communications (AOC), Flight Information Services (FIS) and Airline Passenger Communications (APC). These four categories are described below.

ATC/ATM currently consists of communications between ground controllers and the aircraft flight deck. In addition, air traffic management information is communicated between ground control entities, in particular for flights that cross more than one air traffic control center. Although most air/ground communications today remained voice-based, digital data communications is beginning to be used and will grow rapidly in importance within the next several years. As mentioned above, in a future free flight 
environment, a significant increase in digital data communications will be necessary for ATC/ATM.

AOC consists primarily of fleet management operations for individual airlines. AOC includes departure and arrival times, passenger connections, and gate information, and other communications needed by the airlines for operations management. Aircraft health monitoring and maintenance information is also part of $A O C$. It can also include weather information provided by the airline operations center. The demand for AOC communications is increasing as airlines strive for more efficient operations and newer aircraft designs include more aircraft health and maintenance monitoring.

FIS includes such non-control information as Notices to Airmen, Special Use Airspace status, and advisory weather. Weather is by far the most significant of these in terms of importance to safety as well as the amount of data to be distributed and resulting communications bandwidth requirements. In addition, route planning, especially in a free flight environment, requires accurate weather information. As mentioned above, research programs are now underway by the National Aeronautics and Space Administration (NASA), the Federal Aviation Administration (FAA), the National Center for Atmospheric Research (NCAR) and many others to develop better models and forecasting capabilities, and better weather products delivered to flight decks faster and more accurately. These new weather services will require a considerable increase in the amount of data transmitted to aircraft flight decks. They will also require the transmission of data from aircraft sensors and avionics to the ground in order to improve weather analysis, prediction, and information delivery.

Passenger services represent the largest requirement for future aeronautical communications. In an increasingly electronically connected world, passengers will begin to expect the same level of connectivity in the air as they have become accustomed to on the ground. Some segments of the aviation industry, such as cargo, commuter, and general aviation will present an extremely limited market for passenger communications services. However, the business aviation segment and especially the transport (major airline) segment are expected to provide enthusiastic, paying customers for passenger communications services. The potential passenger services may overwhelm the other communications services in terms of required bandwidth, and from the aircraft operators point of view can be used to pay for the data "pipeline" providing the AOC and FIS services described above, and perhaps even safety critical ATC/ATM communications at some point in the future. Potential passenger services include Internet access, movies and other video, reservations, on-board phone, shopping, gambling, paging, e-mail and fax. A recent study suggests that for the domestic
US market alone, such services could generate $\$ 3.5$ billion in annual revenue, which would easily offset the costs of providing these services and even create profits, as well as funding the non-passenger communication services ${ }^{\circ}$.

\section{Current and Near-Term Aeronautical Communications}

The prevailing communications method for ATC/ATM today remains analog voice. The majority of the analog voice links are ground-based Very High Frequency (VHF) simplex links covering land and near-shore areas, in the $117.975-137 \mathrm{MHz}$ protected aeronautical spectrum. Coverage of oceanic and remote land regions is accomplished using High Frequency ( $\mathrm{HF}$ ) voice links (2.8 - 28 $\mathrm{MHz}$ ) and satellite communications (INMARSAT, L-Band). However, not all aircraft flying remote or oceanic regions are equipped for both satellite and $\mathrm{HF}$ voice communications.

AOC communications are primarily performed using the Aircraft Addressing and Reporting System (ACARS). ACARS is a digital (character-oriented) packet network, which includes priority and preemption capability that allows high priority messages to be delivered ahead of routine messages. Packets are routed through a Central Processing System. ACARS communications occurs over $25 \mathrm{kHz}$ VHF channels in the same band as the VHF analog voice.

Digital data link services are being developed or planned for the VHF spectrum. These are known as VHF Digital Link Mode 2, 3, and 4 (or VDL Mode 2, 3 and 4 ). These services will enable the transition from a primarily analog voice-based aeronautical communications environment to a digital data and digital voice environment.

VDL Mode 2 is in the initial stages of deployment. It will use differentially encoded 8-Phase Shift Keying (D8PSK) modulation in $25 \mathrm{kHz}$ channels to provide raw data throughput of $31.5 \mathrm{kbps}$. The Controller Pilot Data Link Communications (CPDLC) Build 1 program will begin using VDL Mode 2 to provide digital data link services for a subset of basic air traffic control communications messages for the enroute (cruise) phase of flight within the Miami Air Route Control Center beginning in 2002, and then expanding to the entire continental United States. Similar trials, and eventual full deployment, are being developed in Europe as well. AOC services will also be provided using VDL Mode 2 when the infrastructure has been sufficiently deployed and aircraft have been equipped with VDL Mode 2 transceivers. 
VDL Mode 3 is a digital data and voice system currently under development. VDL Mode 3 will employ D8PSK modulation and time division multiple access (TDMA) techniques in order to obtain 4 communications subchannels within a $25 \mathrm{kHz}$ VHF channel, for a total raw data throughput of $31.5 \mathrm{kbps}$ per $25 \mathrm{kHz}$ channel.

VDL Mode 4 is another VHF digital datalink system that is currently under development. GFSK or differential 8PSK modulations will enable raw data throughputs of 19.2 and $31.5 \mathrm{kbps}$, respectively. A selforganizing TDMA access technique will be employed. VDL Mode 4 was recently tested in the Cargo Airlines Association Ohio Valley Experiment. In this experiment. VDL Mode 4 was used to provide Automatic Dependent Surveillance Broadcast (ADS-B) communications. ADS-B broadcasts position, altitude, and other flight data to Air Traffic Control and/or other nearby aircraft and is a vital component of future free flight operations?.

In addition to VHF digital link, an HF data link service is being developed, but will be limited to $1.8 \mathrm{kbps}$ data rates.

The above current and near-term communications methods are used for all ATC/ATM and AOC services. In particular, the ATC/ATM messages are considered safety critical and currently must be performed using controlled and protected VHF aeronautical spectrum.

Several other commercial communications services are available for aeronautical communications. Nonoceanic mobile satellite service for passenger voice services is available from American Mobile Satellite Corporation. Familiar to most airline passengers are phone and low rate data connections offered by AT\&T Wireless and GTE Airphone (in the United States). Aeronautical terminals compatible with the IRIDIUM low earth orbit (LEO) satellite network have been developed. Air Cell is now providing cell phone voice and data service to aircraft. VHF-based commercial broadcast services are beginning to be deployed to provide flight information services (primarily weather), with the intended users being lower altitude general aviation aircraft. All of these services are relatively low data rate FIS and APC application offerings.
The current VHF-based voice communications channels are becoming heavily congested, especially in high-density airspace, such as areas around major airports. This is the primary motivation to move to more efficient digital communications methods. However, the available bandwidth in the protected VHF spectrum is constrained. In addition coverage of oceanic and remote regions using VHF ground-based communications is inadequate, and blockage by terrain in mountainous areas also limits coverage. It is doubtful that even with more efficient digital communications this bandwidth is adequate for future growth of aviation and new communications needs (such as free flight) even if the VHF spectrum is limited only to ATC/ATM and AOC services. NASA is currently engaged in requirements studies to quantify the future capacity needs for aeronautical communications.

\section{Future Aeronautical Communications Trends}

The preceding section described the gradual move from analog voice-based communications to digital data communications, especially for ATC/ATM operations. Multifunction displays in the cockpit will enable the integration of intuitive weather data, terrain and traffic information, increasing communications requirements to and from aircraft. Airlines require greater information collection and dissemination to manage their fleets. Most of all, passenger communications will grow rapidly as video, internet and other data services, on-board shopping and reservations services, and other consumer applications are provided to passengers. Figure 2 depicts how these trends will manifest themselves in terms of aeronautical communications services.

The shift from government owned and controlled communications for aeronautics, already beginning today, will continue as limited protected VHF spectrum is replaced by commercial services in other frequency bands. Hence, the government VHF communications will be an increasingly smaller proportion of the total aeronautical communications. Voice communication, which has dominated for more than 60 years, is already being replaced by some digital data applications. Voice will always be necessary for non-routine and emergency communications, but most other ATC/ATM and AOC communications will become highly 


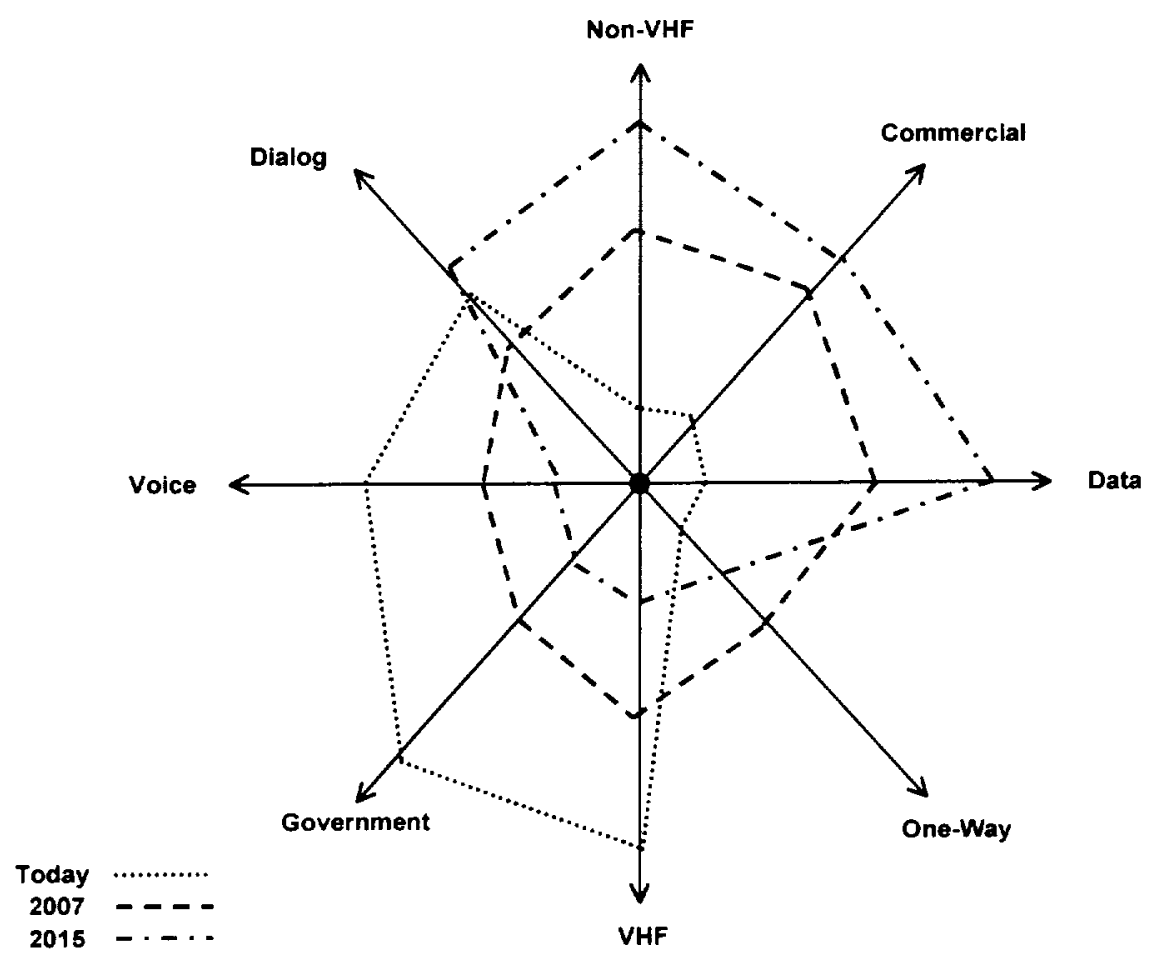

Figure 2 - Future Trends in Aeronautical Communications

automated. especially as free flight is introduced. Oneway communications will increase as broadcast services for FIS and passenger video services are introduced, but dialog based communications will increase later as advanced free flight automation tools are implemented and interactive passenger services are introduced. Overall, the complexity and hybrid nature of the aeronautical communications system will increase for at least the next two decades.

\section{The Growing Role of Satellite Communications}

The capability of satellite communications to provide service in a mobile environment, cover oceanic and remote regions and all flight altitudes, and broadcast information to large geographic areas inexpensively makes it an ideal candidate to cover the gaps in future aeronautical communications requirements noted previously. In addition, satellites have access to broad portions of spectrum enabling much higher bandwidth services than can be obtained in the VHF band. Even higher frequency bands, such as Ka-Band which suffer from significant rain attenuation can be used for nearly all airborne communications while the aircraft is above the rain. The ability of commercial satellite services to provide the required reliability, integrity, availability and security for safety critical communications remains to be adequately proven. However, all other aeronautical communications requirements will likely be able to be met by commercial satellite communications services.

Recently, two United States based airlines have announced the introduction of direct broadcast television on some flights, using mechanically steered antennas for reception of satellite broadcasts installed on newly delivered aircraft. This will likely begin to open the floodgates for passenger communications services. The availability of broadband transmission to aircraft, providing revenue-generating services for passengers can be exploited for AOC and FIS services as well.

Currently, narrowband satellite communications over oceanic regions provide some basic ATC/ATM and AOC connectivity, proving the utility of satellite communications to provide these services where no other communications are available. Using commercial systems (such as LEO voice and data networks) may become sufficiently reliable and cost effective to induce implementation of some ATC/ATM services such as ADS-B.

Other innovative satellite technologies may be able to fill aeronautical communications niches. For example, satellite digital audio radio service (SDARS), which is beginning to be introduced in some parts of the world, may provide an inexpensive method of broadcasting weather data to aircraft. 


\section{The Need for a Hybrid Architecture}

Satellites have already established a role in aeronautical communications. a role that will continue to grow as technical issues such as affordable electronically steered antennas and efficient mobile routing protocols are solved. Although it is conceivable that satellite communications could provide all aeronautical communications services, replacing the multiplicity of current and near-term future communications links, there are a number of reasons why this will not occur.

In the regulatory realm, there is a strong constituency which requires extreme conservatism in the deployment of technologies affecting aviation safety. Even when the technical issues in applying satellite communications to safety of flight, such as reliability, availability, integrity and security, are put to rest, there will continue to be a strong argument in favor of maintaining safety critical communications in secure, protected aeronautical spectrum. An additional issue is one of redundancy. Maintaining a separate VHF link for voice and ATC/ATM communications provides an added measure of protection for an individual aircraft as well as for the aviation system.

The various segments of the aviation industry commercial transport, regional commuter, business aircraft, cargo aircraft, and general aviation - have significantly different needs for communications services. Broadband satellite communications providing an array of passenger services on large transport aircraft are not needed for cargo or general aviation; hence the equipage costs cannot be justified. Affordability is also a particularly strong factor influencing the low-end general aviation community.

Different segments of flight have different communications requirements. While on the ground and entering or leaving the terminal area, the information required by aircraft is of a local nature and it may prove more efficient to broadcast such information from a local ground-based source. En-route information is of a regional or national nature, making satellite broadcast more efficient.

Ultimately, in the absence of regulatory mandates, all equipage issues are decided by economic factors. Aircraft communications equipment, because of certification requirements and the relatively small market of customers compared to the general global electronic communications market, are very expensive. Unless an economic case study indicates a rapid return on investment, aircraft owners and operators will use existing equipment as long as possible. Hence, the legacy of older communications equipment will dictate that new technologies will phase in rather slowly over time. Unless a new technology can be shown to provide an overwhelming reduction in operating costs, original equipment will remain in use for the entire 30-year or longer lifetime of the average aircraft. New technologies are often only cost effective when introduced into new aircraft, or even new aircraft models.

\section{Future Aeronautical Communications Networks}

There are two primary network topologies, which are being developed for application to network-based aeronautical communications. The Aeronautical Telecommunications Network (ATN) is an ICAOendorsed standard for future aeronautical telecommunications, intended to provide a seamless global connectivity for ATC/ATM and AOC applications. The Internet type of network, based on Internet Protocol (IP) technologies can provide communications services for passengers, particular Internet connectivity. It also can potentially provide FIS and AOC services.

The ATN is a data communications internetwork that provides a unique communications service for all Air Traffic Services Communications (ATSC). These services can be either ground to ground or air to ground. Therefore, the ATN can be viewed as both a ground based Internet, for ground/ground users, and as an air/ground Internet for airborne and ground users.

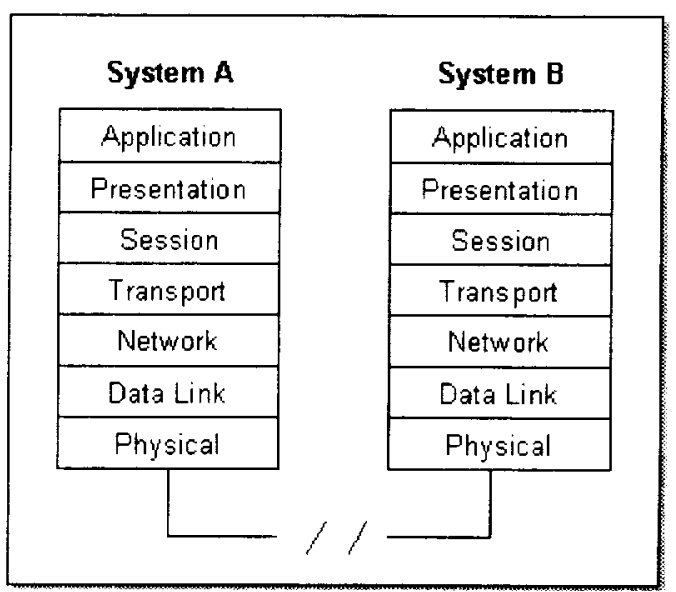

Figure 3 -Aeronautical Telecommunications Network Protocol Model

Functionally, the ATN is composed of three systems: End Systems, Intermediate Systems, and Subnetworks. The End System is essentially an end-user application responsible for communicating with other remote applications. An Intermediate System is also known as an ATN router. Its function is to relay (route) data between different Subnetworks. Subnetworks are simply the interconnection of End Systems and Intermediate Systems. They can be of almost any 
type - VHF data link, Mode S, Ethernet, etc. They must also support packet mode communications and permit each system to be uniquely addressed.

The ATN is based on the International Organization for Standardization (ISO) Open System Interconnection (OSI) Reference model. Whereas the TCP/IP protocol suite represents only five of the ISO layers, ATN addresses all seven ${ }^{8}$. The seven layers of the ISO model are shown in figure 3 .

The ATN is designed to enable any communications subnetwork to be used. A subnetwork in this case is defined as a communications link and supporting system providing physical connectivity between the airbased and ground based routers, as shown in Figure 4 .

The ATN is currently under development and initial implementation and testing is planned to begin shortly. The CPDLC Build 1 trials scheduled for 2002 will use an ATN network with the VDL Mode 2 subnetwork.

An IP-based network is necessary to connect aircraft passengers with Internet based applications, and also can be potentially useful for other aeronautical communications, as noted above. However, the mobile environment presented by a moving aircraft requires a mobile-IP based network. With mobile IP the endsystem is assigned one IP address, which never changes. An end-system using mobile IP is designated as a mobile node. The mobile node is associated with a home agent, a router located at the mobile node's home location. When outside the home network the mobile node communicates with a foreign agent, a router at the new location of the mobile node. When a datagram is sent to the mobile node, the message is intercepted by the home agent and tunneled to the foreign agent for delivery to the mobile node. When the mobile node sends a datagram. it uses its standard IP routing for delivery. Mobile IP is an automated method of communicating with objects moving between subnetworks.

As an example: An aircraft based in Los Angeles is flying from Los Angles to Tokyo, using mobile IP. The aircraft, while in the Los Angeles area has communications directly to its home agent. As it moves

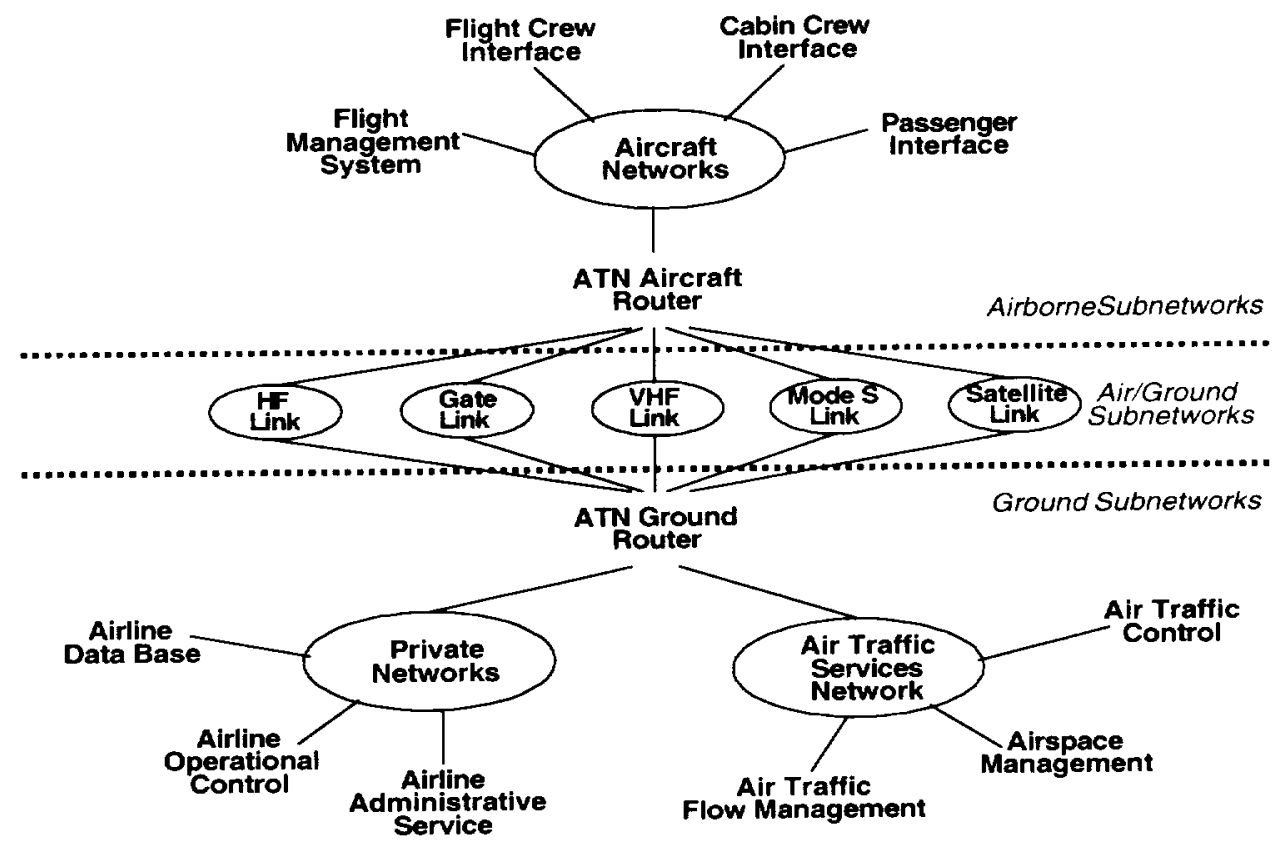

Figure 4 - Structure of the Aeronautical Telecommunications Network

away from the United States coastline it loses its VHF link and picks up a satellite link. The aircraft now registers with the foreign agent on the satellite network for communications. As the aircraft nears Tokyo, it re-registers with a foreign agent in Tokyo for communications. At any point in the journey communications from anywhere can be established to the aircraft, without manual reconfiguration of the IP address or routing information.

Updated versions of both the ATN and IP protocols are expected to be developed in the future. As new IP 
versions, addressing mobility, security, and other issues critical to aeronautical communications, convergence between the ATN and IP protocols on some level may occur.

\section{Simulation and Modeling of Future Aeronautical Communications Systems}

To ensure capacity and safety goals are met, it is necessary to assess the performance of future aeronautical communications systems and networks. To accomplish this, a significant modeling and simulation effort is being started at NASA Glenn. The modelling of communication links, networks, applications and air system traffic will allow evaluation of system performance. Consideration of many issues unique to aeronautical communications is required in such a simulation effort.

The key aeronautical communications issues for future network architectures can be grouped into the following categories.

\section{$\underline{\text { Utilization }}$}

The different segments of aviation have different information and communications requirements. Commercial transport, general aviation, business aviation, cargo, and rotorcraft operate in different portions of airspace, at different types of airports, and may carry from zero to hundreds of passengers. An aeronautical communications architecture must account for all airspace users.

\section{Avionics}

The affordability of aircraft equipage is highly dependent on aviation segment. General aviation aircraft are usually minimally equipped compared to the transport segment. There are also different avionics required for different information requirements. In modelling a communications architecture, the communications capability of all users, dependent on their current equipage as well as their ability to upgrade to new capabilities, must be considered. Additional issues include the effects of using open rather than proprietary standards for information format, data transmission protocols, services and applications, etc. In proposing improvements to the system, the issue of whether system changes are made mandatory by regulatory agencies or are induced by economic considerations comes into play.

\section{Service provider}

Aeronautical communications, especially safety critical and operational communications, and much of the flight information service communications, are currently provided through government owned or operated infrastructures, or using government controlled frequencies. With limited expansion available in these constrained frequency bands, what services and applications can be performed using commercial service providers over commercial frequency spectrum?

\section{Phase of Flight}

Phases of flight include planning, surface movement, terminal area (takeoff and landing), and en-route. The information and communications needs vary significantly over these different flight phases. Terminal area communications are particularly intensive and critical for maintaining safe separation while gaining maximum airport operating capacity. Severe local weather is also very important for terminal area operations. Passenger services, however, are normally made available during the en-route phase of flight. A simulation of aeronautical communications must therefore include dynamically changing communications requirements for aircraft.

\section{Delivery mechanism}

Different information dissemination requirements are met by different delivery mechanisms. Voice and/or data, simplex or duplex links, broadcast, multicast, or addressable, all must be modelled.

\section{Coverage}

Various aeronautical communications applications require local, regional, or global coverage - oceanic and remote areas have special needs. The capabilities of different communications link to cover geographic areas must be considered, including such issues as coverage as a function of altitude and blockage of line-of-sight communications by terrain obstacles.

\section{Link Characteristics}

The availability of protected spectrum, bandwidth limitations, propagation characteristics, modulation, coding, and access techniques must be included in aeronautical communications systems models. The impact of reduced quality of service at the edge of coverage, handoff between different types of communications links, different latency for satellite and terrestrial links, and many other issues will affect network and system performance and must be accurately modelled.

\section{Quality of Service}

Priority of safety critical messages, timeliness of information, availability, redundancy/robustness, and 
data integrity and security are critical issues. The aeronautical communications architecture must enable all critical messages to reach their destination in a timely and error-free fashion, even in high density airspace. Quality of service issues impact the efficient performance of the system and its networks, and will effect the choice of communications links, modulation and coding, access techniques, required number of channels, and many other parameters.

\section{Summary}

Future aeronautical communications systems are already migrating from ground-based VHF analog voice communications in protected aeronautical spectrum to a digital data based hybrid of ground and satellite links using both government and commercial services. This trend will continue for at least the next two decades, as the demand for information within the aviation community grows rapidly and protected VHF spectrum becomes inadequate to handle the load. The majority of this growth, in terms of raw bandwidth requirements, will come from passenger services. However, important capacity and safety improvements in the national and global airspace will require substantial increases in communications capacity as well. The hybrid approach for future aeronautical communications is necessary to satisfy many economic, safety, and legacy issues. The increasing complexity of aeronautical communications and the introduction of ATN and mobile IP networks to the aviation environment requires that a total aeronautical communications system architecture approach be employed to assess and optimize the performance of the system. The NASA John H. Glenn Research Center is currently developing a modelling and simulation effort to provide such a communications architecture approach in order to support specific NASA programs for the improvement of aviation system capacity and safety.

\section{References}

1. ICAO News Release PIO 26/97, 23 December 1997, "World Airline Traffic and Load Factors Highest Ever in 1997."

2. ICAO News Release PIO 4/97, March 1997. "Growth in Air Traffic to Continue: ICAO Releases Long-Term Forecasts."

3. Perry, T. S., "In Search of the Future of Air Traffic Control", IEEE Spectrum, August 1997.

4. Final Report of RTCA Task Force 3 on Free Flight Implementation, October 26, 1995.

5. National Aviation Weather Program, Strategic Plan, April 1997.

6. NASA Advanced Air Transportation Technologies (AATT) Program Free Flight Satellite Communication Study, Final Report, Lockheed Martin Aeronautical Systems, for NASA Lewis Research Center, August, 1998.

7. NASA Contractor Report "Communications System Architecture Development for Air Traffic Management and Aviation Weather Dissemination (TO-24)", Publication Pending.

8. NASA Contractor Report CR-2000-209922, "Aeronautical Related Applications Using ATN and TCP/IP Research Report", Computer Networks and Software, Inc., November 1999. 


\section{REPORT DOCUMENTATION PAGE}

Form Approved

OMB No. 0704-0188

Public reporting burden for this collection of information is estimated to average 1 hour per response, including the time for reviewing instructions, searching existing data sources, gathering and maintaining the data needed, and completing and reviewing the collection of information. Send comments regarding this burden estimate or any other aspect of this

Davis Highway. Suite 1204. Arlington, VA 22202-4302, and to the Office of Management and Budget, Paperwork Reduction Project (0704-018B), Washington, DC 20503.

\begin{tabular}{|l|l|l} 
1. AGENCY USE ONLY (Leave blank) & $\begin{array}{c}\text { 2. REPORT DATE } \\
\text { April } 2000\end{array}$ & $\begin{array}{r}\text { 3. REPORT TYPE AND DATES COVERED } \\
\text { Technical Memorandum }\end{array}$
\end{tabular}

4. TITLE AND SUBTITLE

5. FUNDING NUMBERS

A Hybrid Satellite-Terrestrial Approach to Aeronautical

Communication Networks

6. AUTHOR(S)

Robert J. Kerczewski, Gerald J. Chomos, James H. Griner, Steven W. Mainger,

Konstantinos S. Martzaklis, and Brian A. Kachmar

7. PERFORMING ORGANIZATION NAME(S) AND ADDRESS(ES)

National Aeronautics and Space Administration

John H. Glenn Research Center at Lewis Field

Cleveland, Ohio 44135-3191

WU-576-01-21-00

\section{SPONSORING/MONITORING AGENCY NAME(S) AND ADDRESS(ES)}

National Aeronautics and Space Administration

Washington, DC 20546-0001
8. PERFORMING ORGANIZATION REPORT NUMBER

$E-12225$
10. SPONSORINGMONITORING AGENCY REPORT NUMBER

NASA TM-2000-210028

AIAA 2000-1213

\section{SUPPLEMENTARY NOTES}

Prepared for the 18th International Communications Satellite Systems Conference sponsored by the American Institute of Aeronautics and Astronautics, Oakland, California, April 10-14, 2000. Robert J. Kerczewski, Gerald J. Chomos, James H. Griner, Steven W. Mainger, and Konstantinos S. Martzaklis, NASA Glenn Research Center; Brian A. Kachmar, Analex Corporation. 3001 Aerospace Parkway, Brook Park, Ohio 44142. Responsible person, Robert J. Kerczewski, organization code 5610. (216) 433-3434.

12a. DISTRIBUTION/AVAILABILITY STATEMENT 12b. DISTRIBUTION CODE

Unclassified - Unlimited

Subject Category: 04

Distribution: Nonstandard

This publication is available from the NASA Center for AeroSpace Information. (301) 621-0390.

13. ABSTRACT (Maximum 200 words)

Rapid growth in air travel has been projected to continue for the foreseeable future. To maintain a safe and efficient national and global aviation system, significant advances in communications systems supporting aviation are required. Satellites will increasingly play a critical role in the aeronautical communications network. At the same time, current ground-based communications links, primarily very high frequency (VHF), will continue to be employed due to cost advantages and legacy issues. Hence a hybrid satellite-terrestrial network, or group of networks, will emerge. The increased complexity of future aeronautical communications networks dictates that system-level modeling be employed to obtain an optimal system fulfilling a majority of user needs. The NASA Glenn Research Center is investigating the current and potential future state of aeronautical communications, and is developing a simulation and modeling program to research future communications architectures for national and global aeronautical needs. This paper describes the primary requirements, the current infrastructure, and emerging trends of aeronautical communications, including a growing role for satellite communications. The need for a hybrid communications system architecture approach including both satellite and ground-based communications links is explained. Future aeronautical communication network topologies and key issues in simulation and modeling of future aeronautical communications systems are described.

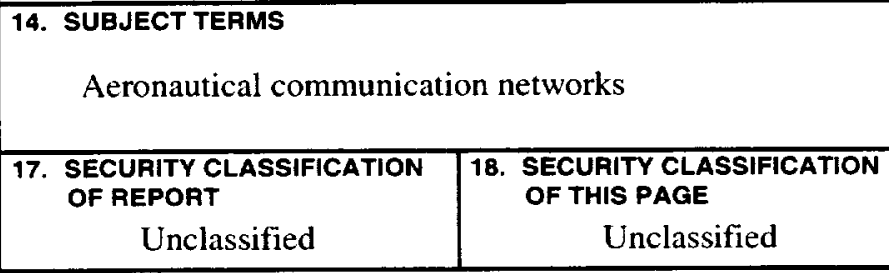

NSN 7540-01-280-5500
19. SECURITY CLASSIFICATION OF ABSTRACT Unclassified

